\title{
Reliability Analysis of Centrifugal Pump through FMECA and FEM
}

\author{
SELVAKUMAR $\mathbf{J}^{1 *}$ and NATARAJAN $\mathrm{K}^{2}$ \\ ${ }^{1}$ SNS College of Technology, Coimbatore, INDIA \\ ${ }^{2}$ PSG College of Technology, Coimbatore, INDIA
}

(Received on September 06, 2016 Revised on December 13, 2016)

\begin{abstract}
This research article presents a methodology to identify the critical component of a centrifugal pump and analyze its reliability. Failure analysis of major components of the pump was done, risk priority number was calculated and critical component was identified. The critical component was considered to be composed of two sections. Its reliability was analyzed by mathematical modeling of the first section. A finite element model of the component was developed and stress analysis was done using finite element method, in order to assess the reliability index of the second section. Total reliability of the component was calculated by multiplying the two reliability indices.
\end{abstract}

Keywords: Risk priority number, critical component, impeller, fatigue, reliability index

\section{Introduction}

Component failure adversely affects the performance and reliability of a centrifugal pump. A pump must function reliably under specified operating conditions in the process industries in order to ensure the continuous operation of the plant. Reliability analyses of various components of a centrifugal pump have been carried out in manufacturing, processing and service industries, to identify the causes of component failure and their effects on system reliability.

The failure modes of pump components such as seal, bearing, impeller and shaft have been considered in the analysis of centrifugal pump failures [1]. Design deficiency, material defect, processing error, assembly defects, off-design operation, maintenance deficiency and improper operation are listed as the root causes of a pump failure [2]. Improper heat treatment was identified as the primary cause of failure of a countershaft in a centrifugal pump in a power plant application [3]. Material properties, flow characteristics and torsional vibrations have been considered as important factors in the analysis of the failure modes of a six-stage centrifugal pump impeller [4]. Finite element method and experimental testing have been employed in the analysis of failure-equivalent stress in the volute casing of a centrifugal pump by taking six sample casings [5]. Breakage problems occurring in the impellers of an eight-stage centrifugal pump were analyzed, fatigue was identified as the failure mechanism and proper heat treatment was suggested as the remedial measure [6]. Useful life of centrifugal pump components and the major types of problems occurring in the pump were analyzed by conducting a survey among the domestic, agricultural and industrial pump users [7]. Numerical simulation and experimental methods have been adopted to analyze the effects of pressure pulsations on the impeller of a double volute centrifugal pump [8]. Partial derivative rule is applied in calculating the reliability of automobile components such as connecting rod, rear axle 
housing and coil spring [9]. Stress-strength interference theory is applied in analyzing the reliability of rotary systems such as gear mounted on shaft and shaft-fan assembly [10].

In this research paper, a new methodology has been devised which involves five major steps namely: (1) implementation of FMECA method to identify the critical component of a centrifugal pump; (2) use of reliability block diagram to determine the logical relationship between the impeller sections; (3) application of stress-strength interference theory to calculate reliability indices; (4) development of a mathematical model incorporating strength reduction factors or derating factors to compute the corrected fatigue strength of the impeller keyway section; (5) use of finite element method to predict the failure equivalent stress developed in the blade section of the impeller.

The objective of this research paper is to analyze the reliability of the critical component of centrifugal pump. Data pertaining to the failure of pump components were collected from the pump industry and failure mode effects and criticality analysis was done on the collected data. The component with the highest value of Risk priority number (RPN) was identified as the critical component. This paper sets the direction for future research work related to improving the reliability of a centrifugal pump by identifying impeller as its critical component and calculating its reliability. Reliability of the impeller can be improved by incorporating suitable design modifications such as making changes in material selection and its geometrical parameters.

\section{Research Methodology}

Failure modes, effects, and criticality analysis (FMECA) technique is used to identify the main failure modes of the pump components. It is a systematic procedure employed in this research work for analyzing the failure modes of pump components. Risk priority number prioritizes the relative importance of each failure mode and its effect. Reliability of the critical component, identified based on RPN value, is analyzed using mathematical modeling and numerical simulation methods. Strength of the impeller material and the applied load are considered to be normally distributed, for the purpose of reliability assessment.

Fatigue strength of the impeller material at the keyway section is modified by incorporating derating factors. Failure equivalent stress in the impeller blade section was obtained through finite element method, by subjecting the mesh model to hydraulic loading. Total reliability of the impeller was calculated by multiplying the reliability values of its two sections.

\subsection{Risk Priority Number}

Three major factors involved in the calculation of RPN are severity, occurrence and detection of a failure. Severity refers to the potential severity of failure of a pump component and its effect on the pump performance. A rating scale of 1-10 was employed for rating the severity of failure. If there is no effect on the system due to component failure, its severity is given a rank value of 1 . Hazardous failure of a part which happens without any warning is assigned a rank of 10 . Occurrence refers to the likelihood of occurrence of failure in a pump component. A 10-point rating scale was used for ranking the occurrence of failure. An unlikely failure is assigned a rank of 1, while a failure which 
is very likely to occur is given a rank of 10 . Detection indicates the probability of detecting the component failure. The probability of failure detection is rated on a 10-point scale. If the detection of a failure is almost certain the rank value of 1 is assigned, whereas absolute uncertainty of failure detection is given a rank of 10 .

RPN values of a pump component range from 1 to 1000 , where ' 1 ' indicates an unlikely and insignificant failure and ' 1000 ' implies a certain and hazardous failure. The calculation of RPN values for the failures in pump components is illustrated in Table 1. The RPN values for each failure mode are calculated by multiplying the corresponding values of severity, occurrence and detection. Since impeller has the highest RPN value of 126 , it is identified as the critical component of centrifugal pump. In order to improve the reliability of impeller and reduce the risk of failure, suitable modifications are to be incorporated in the impeller design. Major design features pertaining to the impeller are its material properties, surface finish, geometrical dimensions and blade angles. One of the main failure mechanisms of impeller failure is fatigue, which occurs when a member is subjected to repeated, reversed cyclic stresses. Fatigue failure begins with a minute crack, at a point of discontinuity in a component, which propagates rapidly resulting in the rupture of component. Fatigue strength of a component, which indicates its load-bearing capacity under cyclic loading conditions, is affected by discontinuities and sharp corners in the component.

Table 1: Calculation of Risk Priority Number for Pump Components

\begin{tabular}{|c|c|c|c|c|c|c|c|c|}
\hline $\begin{array}{l}\text { S. } \\
\text { No. }\end{array}$ & Part & $\begin{array}{l}\text { Failure } \\
\text { Mode }\end{array}$ & $\begin{array}{c}\text { Failure } \\
\text { Effect }\end{array}$ & $\begin{array}{c}\text { Failure } \\
\text { Mechanism }\end{array}$ & $\begin{array}{l}\text { Severity } \\
\text { (S) }\end{array}$ & $\begin{array}{c}\text { Occurrenc } \\
\text { e (O) }\end{array}$ & $\begin{array}{l}\text { Detection } \\
\text { (D) }\end{array}$ & RPN \\
\hline \multirow{2}{*}{1} & \multirow{2}{*}{ Seal } & Leakage & $\begin{array}{c}\text { Pump } \\
\text { Leakage }\end{array}$ & Distortion & $\begin{array}{l}\text { Minor } \\
\text { (3) }\end{array}$ & $\begin{array}{l}\text { Moderate } \\
\text { (5) }\end{array}$ & $\begin{array}{l}\text { Very High } \\
\text { (2) }\end{array}$ & 30 \\
\hline & & $\begin{array}{c}\text { Excessive } \\
\text { Wear }\end{array}$ & $\begin{array}{c}\text { Seal } \\
\text { Damage }\end{array}$ & Erosion & $\begin{array}{l}\text { Minor } \\
\text { (3) }\end{array}$ & $\begin{array}{l}\text { Moderate } \\
\text { (5) }\end{array}$ & $\begin{array}{l}\text { Very High } \\
\text { (2) }\end{array}$ & 30 \\
\hline \multirow{2}{*}{2} & \multirow{2}{*}{ Bearing } & Overheat & Seizure & $\begin{array}{l}\text { Insufficient } \\
\text { Lubrication }\end{array}$ & $\begin{array}{l}\text { Significant } \\
\text { (6) }\end{array}$ & $\begin{array}{c}\text { Relatively } \\
\text { Low } \\
(4)\end{array}$ & $\begin{array}{l}\text { Very High } \\
\text { (2) }\end{array}$ & 48 \\
\hline & & $\begin{array}{l}\text { Premature } \\
\text { Failure }\end{array}$ & $\begin{array}{l}\text { Excess } \\
\text { Noise }\end{array}$ & Misalignment & $\begin{array}{l}\text { Significant } \\
\text { (6) }\end{array}$ & $\begin{array}{c}\text { Relatively } \\
\text { Low } \\
\text { (4) }\end{array}$ & $\begin{array}{l}\text { Very High } \\
\text { (2) }\end{array}$ & 48 \\
\hline \multirow{2}{*}{3} & \multirow{2}{*}{ Shaft } & Deflection & $\begin{array}{c}\text { Excess } \\
\text { Vibration }\end{array}$ & Overload & $\begin{array}{c}\text { Significant } \\
\text { (6) }\end{array}$ & $\begin{array}{c}\text { Low } \\
\text { (3) }\end{array}$ & $\begin{array}{l}\text { High } \\
\text { (3) }\end{array}$ & 54 \\
\hline & & $\begin{array}{c}\text { Excessive } \\
\text { Wear }\end{array}$ & $\begin{array}{c}\text { Shaft } \\
\text { Damage }\end{array}$ & Fretting & $\begin{array}{c}\text { Significant } \\
\text { (6) }\end{array}$ & $\begin{array}{l}\text { Low } \\
\text { (3) }\end{array}$ & $\begin{array}{l}\text { High } \\
\text { (3) }\end{array}$ & 54 \\
\hline \multirow{2}{*}{4} & \multirow{2}{*}{ Impeller } & $\begin{array}{c}\text { Crack } \\
\text { Formation }\end{array}$ & $\begin{array}{l}\text { Impeller } \\
\text { Breakage }\end{array}$ & Fatigue & $\begin{array}{l}\text { Major } \\
\text { (7) }\end{array}$ & $\begin{array}{l}\text { Low } \\
\text { (3) }\end{array}$ & $\begin{array}{l}\text { Low } \\
\text { (6) }\end{array}$ & 126 \\
\hline & & Deformation & Fracture & Cavitation & $\begin{array}{l}\text { Major } \\
(7)\end{array}$ & $\begin{array}{l}\text { Low } \\
\text { (3) }\end{array}$ & $\begin{array}{l}\text { Low } \\
(6)\end{array}$ & 126 \\
\hline 5 & Casing & $\begin{array}{c}\text { Crack } \\
\text { Formation }\end{array}$ & $\begin{array}{c}\text { Casing } \\
\text { Breakage }\end{array}$ & $\begin{array}{c}\text { Pressure } \\
\text { Pulsation }\end{array}$ & $\begin{array}{c}\text { Serious } \\
\text { (9) }\end{array}$ & $\begin{array}{l}\text { Very Low } \\
\text { (2) }\end{array}$ & $\begin{array}{l}\text { High } \\
\text { (3) }\end{array}$ & 54 \\
\hline
\end{tabular}

\section{Reliability Analysis}

Reliability block diagram (RBD) illustrates the logical relationship between the components of a system. The system is divided into subsystems in order to analyze the effect of their failure on the performance of the system. If a series configuration system has to perform its function successfully, all the subsystems must be in operation. The formulation of RBD is the initial step for evaluating the system reliability.

According to interference theory, a mechanical component fails due to extremely small values of strength or extremely large values of load. The component is considered to 
be safe and reliable when its strength exceeds the value of load. Failure occurs when the applied load is greater than the material strength. The interference area of the probability density function curves of stress and strength represents the failure zone. In order to improve the reliability of the component its interference area has to be reduced through process control and quality control methods.

\subsection{Reliability of the Impeller (R)}

Impeller is the rotating part of a pump which lifts or transfers fluid from one place to another by means of centrifugal force. It is held in position on the shaft by means of a key inserted in the keyway section. Impeller is considered as composed of two sections, namely keyway section and blade section for the purpose of calculating its reliability. The reliability values of keyway section and blade section are denoted by the terms $R_{1}$ and $R_{2}$ respectively. Power is transmitted to impeller through the shaft in the keyway section. Torque input to the shaft is provided by the electric motor. Due to rotation of the impeller mounted on the shaft, liquid flow occurs in the blade section.

Reliability block diagram of a system shows the functional relationship between the components, in terms of failure. In the case of impeller the series arrangement of keyway and blade sections is illustrated in Figure 1. Reliability of a system with two components in series is the product of component reliability values. Hence, the total reliability of the impeller is the product of reliability values of the two sections, $R_{1}$ and $R_{2}$.

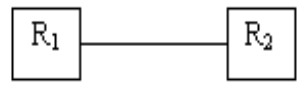

Figure 1: Reliability Block Diagram for the Impeller Sections

\subsection{Stress - Strength Interference}

Impeller is considered to be safe and reliable when its strength (Ş) exceeds the load (L) acting on it. Mean and standard deviation values for the load and strength are to be determined in order to compute the reliability of impeller. Strength of the impeller and load acting on it are considered to follow normal distribution. Margin of safety (M) is given by the difference between the values of strength and load. The notations used for mean and standard deviation values are as follows: (i) strength of the impeller material$\mu_{\mathrm{s}}, \sigma_{S}$; (ii) load acting on the impeller- $\mu_{\mathrm{L}}, \sigma_{\mathrm{L}}$; and (iii) margin of safety- $\mu_{\mathrm{M}}, \sigma_{\mathrm{M}}$. Reliability of the impeller $\mathrm{R}$ is the probability that the value of $\mathrm{M}$ is greater than or equal to zero. When Ş and $\mathrm{L}$ are independent and normally distributed, $\mathrm{M}$ is also normally distributed.

Reliability index $(\beta)$ is a probabilistic measure of safety which is commonly used in structural reliability assessment. Its value is affected by the mean and standard values of strength and load, and the levels at which the distribution curves of strength and load intersect each other. It is the inverse of coefficient of variation. Reliability index $(\beta)$ is calculated based on the mean and standard deviation values of strength and applied load on the impeller as given in equation (1). Reliability of the component is obtained from the standard normal distribution table for the corresponding $\beta$ value. Impeller reliability is calculated using the equation (2). 


$$
\begin{aligned}
& \beta=\left\{\frac{\left(\mu_{S}-\mu_{L}\right)}{\sqrt{ }\left[\left(\sigma_{\Im}\right)^{2}-\left(\sigma_{L}\right)^{2}\right]}\right\} \\
& R=\phi\left\{\frac{\left(\mu_{\overparen{S}}-\mu_{L}\right)}{\sqrt{ }\left[\left(\sigma_{S}\right)^{2}-\left(\sigma_{L}\right)^{2}\right]}\right\}
\end{aligned}
$$

\subsection{Shear Stress Acting on Impeller Keyway Section}

The fatigue strength of a component is different from that of the standard test specimen due to factors such as dimensions and operating conditions factors. These factors termed as derating factors are applied to the empirical fatigue strength value to suit the actual component. In the case of impeller, surface finish, size, loading, reliability and notch effect are considered as derating factors. A notch such as keyway in a shaft is abrupt change in cross-section which raises the stresses locally. Brittle materials such as cast iron are more notch-sensitive.

The dimensional features of key in the impeller keyway section are length $(\mathrm{L})-32.5$ $\mathrm{mm}$ and width (W) - $5 \mathrm{~mm}$. Input torque (T) is calculated based on the values of input power and shaft speed and its value is $19.07 \mathrm{Nm}$; and the mean value of shear stress acting on keyway section $\left(\mu_{\mathrm{s}}\right)$ is calculated as $11.74 \mathrm{MPa}$. The empirical value of endurance limit or fatigue strength $\left(\mu_{\mathrm{E}}\right.$ ') of impeller material - cast iron is $69 \mathrm{MPa}$. This fatigue strength value is modified by the derating factors such as surface finish factor $\left(\mathrm{K}_{\mathrm{a}}\right)$, size factor $\left(\mathrm{K}_{\mathrm{b}}\right)$, loading factor $\left(\mathrm{K}_{\mathrm{c}}\right)$, reliability factor $\left(\mathrm{K}_{\mathrm{d}}\right)$ and notch effect factor $\left(\mathrm{K}_{\mathrm{e}}\right)$. Corrected fatigue strength given by equation (3) is obtained by multiplying these factors with the empirical fatigue strength value.

$$
\mu_{E}=\mathrm{K}_{a} \times \mathrm{K}_{b} \times \mathrm{K}_{c} \times \mathrm{K}_{d} \times \mathrm{K}_{e} \times \mu_{E}^{\prime}
$$

Surface finish factor $\mathrm{K}_{\mathrm{a}}=1$; size factor $\mathrm{K}_{\mathrm{b}}=0.726$; loading factor $\mathrm{K}_{\mathrm{c}}=0.58$, reliability factor $\mathrm{K}_{\mathrm{d}}=0.702$; notch effect factor $\mathrm{K}_{\mathrm{e}}=0.714$. Corrected Fatigue strength $\left(\mu_{\mathrm{E}}\right)$ is calculated as $14.56 \mathrm{MPa}$. Standard deviation value of fatigue strength $\left(\sigma_{\mathrm{E}}\right)=0.08$ * $\mu_{\mathrm{E}}=1.165 \mathrm{MPa}$. Shear stress $\left(\mu_{\mathrm{S}}\right)$ developed in the keyway section of the impeller is obtained by the equation (4).

$$
\mu_{s}=\left[\frac{2 \times T}{(L \times W \times D)}\right]
$$

Coefficient of variation $(\gamma)$ is the ratio of standard deviation to mean value of a parameter. When the partial derivative rule is applied to the shear stress equation (4), the standard deviation value of shear stress $\left(\sigma_{\mathrm{s}}\right)$ is obtained as given by equation (5).

Coefficient of variation value for shear stress obtained by combining the related terms and by further simplification is given in equation (6).

$$
\begin{aligned}
& \sigma_{s}^{2}=\left[\left(\frac{\partial \mu_{s}}{\partial T}\right)^{2} \cdot{\sigma_{T}}^{2}\right]+\left[\left(\frac{\partial \mu_{s}}{\partial L}\right)^{2} \cdot \sigma_{L}{ }^{2}\right]+\left[\left(\frac{\partial \mu_{s}}{\partial W}\right)^{2} \cdot \sigma_{W}{ }^{2}\right]+\left[\left(\frac{\partial \mu_{s}}{\partial D}\right)^{2} \cdot \sigma_{D}{ }^{2}\right] \\
& \gamma_{s}{ }^{2}=\gamma_{T}{ }^{2}+\gamma_{L}{ }^{2}+\gamma_{D}{ }^{2}
\end{aligned}
$$

\subsection{Numerical Example}

The pump selected for reliability analysis is a single-stage, end suction type, radial flow centrifugal pump. Specifications of the centrifugal pump are given by the following data. 
Total head (H) - 25.4 metres; Discharge (Q) - 16 litres per second (lps); Speed (N) - 2800 rpm; Pump Size - 80mm X 65 mm; Input power (P) - 7.5 H.P. or $5.59275 \mathrm{~kW}$; Shaft diameter (D) $-20 \mathrm{~mm}$.

The impeller is of closed type, where the blades are covered with shrouds on both the sides. This arrangement provides a smooth passage for the liquid and wear is minimum. It ensures full capacity operation with high efficiency for prolonged running time. The vanes of the impeller are backward curved in a direction opposite to that of rotation. This type of vane arrangement reduces the formation of eddies and flow reversal. Dimensional details of the impeller are illustrated in Figure 2. Impeller eye diameter $\left(\mathrm{d}_{\mathrm{i}}\right)=80.5 \mathrm{~mm}$; Impeller outer diameter $\left(\mathrm{d}_{\mathrm{o}}\right)=161 \mathrm{~mm}$; Overall width $(\mathrm{W})=65 \mathrm{~mm}$; Width at outlet $\left(\mathrm{W}_{\mathrm{o}}\right)=24$ $\mathrm{mm}$; Vane gap $\left(\mathrm{B}_{2}\right)=14 \mathrm{~mm}$; wall thickness $=5 \mathrm{~mm}$, blade thickness $=5 \mathrm{~mm}$. Impeller material is cast iron grade-200 with a fatigue strength value of $69 \mathrm{MPa}$. Impeller is mounted on the pump shaft and is held in position by means of a key inserted in the keyway. Kinetic energy is imparted to the fluid by the impeller due rotary motion and centrifugal action.

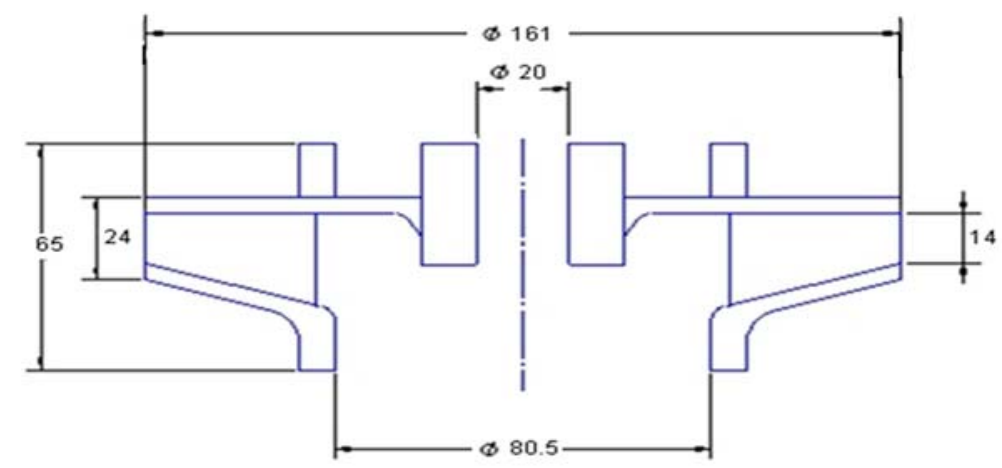

Figure 2: Dimensional Details of the Impeller

\subsubsection{Pressure Load on the Impeller Bblades}

Tangential velocity of impeller at inlet $\left(\mathrm{U}_{1}\right)$ is calculated as $12.46 \mathrm{~m} / \mathrm{s}$ and velocity of flow at impeller inlet $\left(\mathrm{V}_{\mathrm{f} 1}\right)$ is $3 \mathrm{~m} / \mathrm{s}$. Tangential velocity of impeller at outlet $\left(\mathrm{U}_{2}\right)$ is $23.5 \mathrm{~m} / \mathrm{s}$ and velocity of flow at impeller outlet $\left(\mathrm{V}_{\mathrm{f} 2}\right)$ is $2.1 \mathrm{~m} / \mathrm{s}$. Total Head $(\mathrm{H})$ is calculated as $32.22 \mathrm{~m}$. Suction pressure $\left(\mathrm{P}_{1}\right)$ is $5 \mathrm{~m}$. of water and outlet pressure $\left(\mathrm{P}_{2}\right)$ is $0.4 \mathrm{MPa}$; Test Pressure for finite element analysis $\left(\mathrm{P}_{\text {test }}\right)$ is determined as 1.5 times the value of outlet pressure and its value is $0.6 \mathrm{MPa}$.

\subsubsection{Stress Acting on the Impeller Blade Section}

Finite element method is a numerical procedure to obtain approximate solution to engineering problem, in this case the stress developed in the impeller. Stress analysis of the impeller was done through finite element method using the software ANSYS Workbench. The three stages of the method are pre-processing, solving and postprocessing. In the pre-processing stage, solid model of the impeller created using Pro-E was imported for the analysis. Impeller geometry is checked for proper connectivity and mesh generation is done to discretize the solution region that is impeller, into elements. The element type selected for three dimensional modelling is 10 -node tetrahedral element 
of type solid 187. Its essential properties are plasticity, hyper-elasticity and large strain capabilities. This element has three degrees of freedom at each node which are translatory movements along $\mathrm{x}, \mathrm{y}$ and z-axes and no rotational movement. Number of nodes is 1,94 , 651 and the number of elements is $1,06,537$. Mesh model of the impeller is shown in Figure 3.

For this impeller model, the following material properties of cast iron grade-200 are defined: density- $7200 \mathrm{~kg} / \mathrm{m}^{3}$; modulus of elasticity- $97 * 10^{9} \mathrm{~N} / \mathrm{m}^{2}$; Poisson ratio -0.28 . The values of yield strength, ultimate strength and fatigue strength are taken as $98 \mathrm{MPa}$, $140 \mathrm{MPa}$ and $69 \mathrm{MPa}$ respectively for the purpose of stress analysis. The boundary conditions imposed on the model are total pressure at inlet and static pressure at outlet. The problem of singularity is eliminated by providing proper boundary conditions. Test pressure applied by hydraulic loading is $0.6 \mathrm{MPa}$, as detailed in the previous section of this paper.

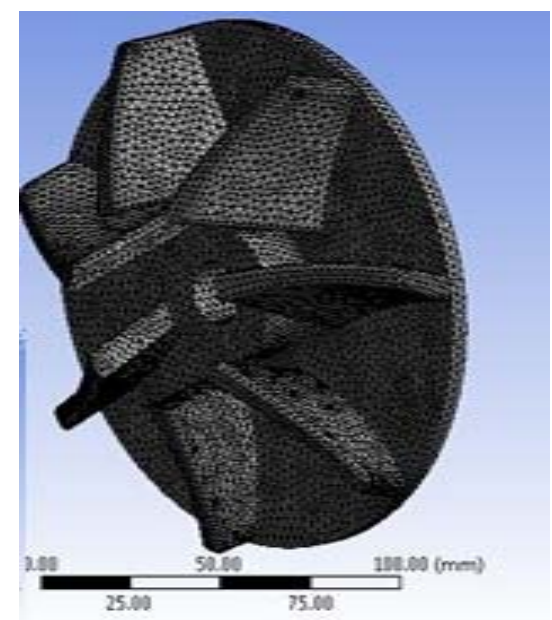

Figure 3: Mesh Model of the Impeller

In the solving stage, the software automatically generates matrices and solves the equations to determine stresses and nodal displacements. During post-processing stage, solutions and quantities related to the stress analysis are displayed graphically. The colour-coded contour plots for the failure equivalent stress developed in the impeller helps in visualizing the regions of maximum principal stress.

\section{Results and Discussion}

\subsection{Reliability of the impeller at the Keyway section $\left(R_{1}\right)$}

Analysis of strength of the impeller keyway section is done by calculating the corrected fatigue strength of the keyway section by using equation (3). The coefficient of variation value for input torque $\left(\gamma_{\mathrm{T}}\right)$ is taken as 0.08 . On the basis of tolerance theory and 3-sigma principle, standard deviation values for the shaft diameter, keyway length and keyway width are taken as 0.005 times their respective mean values. Hence coefficient of variation values for diameter, length and width are given by equation (7). 


$$
\gamma_{D}=\gamma_{L}=\gamma_{W}=0.005
$$

These values are substituted in equation (6) to obtain the $\gamma_{\mathrm{S}}$ value of 0.08047 . The standard deviation value of the shear value of stress $\left(\sigma_{S}\right)$ is obtained by multiplying the coefficient of variation value $\left(\gamma_{\mathrm{S}}\right)$ from the simplified partial derivative rule equation (6) with and mean value $\mu_{\mathrm{S}}$ obtained from equation (4). It is calculated as $0.945 \mathrm{MPa}$. Reliability of the keyway section is computed by substituting the corresponding stress and strength values in equations (1) and (2).Reliability index $\beta_{1}$ is computed as 1.88 . From Standard normal distribution function table, for $\beta_{1}$ value of 1.88 , reliability of the impeller at the keyway section $\left(R_{1}\right)$ is found to be 0.97 .

\subsection{Reliability of the impeller at the Blade section $\left(\mathbf{R}_{2}\right)$}

The mesh model of the impeller is subjected to hydraulic loading and the contour plot of the failure equivalent stress is displayed after post-processing. Maximum stress $\left(\mu_{\mathrm{s}}\right)$ obtained by stress analysis, occurred in the leading edge portion of the impeller and its value is found to be $50.5 \mathrm{MPa}$ as indicated in Figure 4. In the blade section of the impeller, fatigue strength of the material is taken as the mean value of strength $\left(\mu_{\mathrm{E}}{ }^{\prime}\right)$ which is $69 \mathrm{MPa}$ and failure-equivalent stress obtained by Finite element analysis is taken as the mean value of stress $\left(\mu_{\mathrm{S}}\right)$. Standard deviation value of stress $\left(\sigma_{\mathrm{S}}\right)$ is taken as $10 \%$ of its mean value and is computed a as $5.05 \mathrm{MPa}$. Standard deviation value of strength $\left(\sigma_{\mathrm{L}}\right)$ is assumed as $8 \%$ of its mean value $\mu_{\mathrm{E}}$ ' and is calculated as is $5.52 \mathrm{MPa}$. These values are substituted in equations (1) and (2) to obtain the reliability of impeller in the blade section. Reliability index of impeller at blade section $\left(\beta_{2}\right)$ is calculated as given by equation (8).

$$
\beta_{2}=\left\{\frac{\left(\mu_{E^{\prime}}-\mu_{S}\right)}{\sqrt{\left[\left(\sigma_{E^{\prime}}\right)^{2}-\left(\sigma_{S}\right)^{2}\right]}}\right\}=2.47
$$

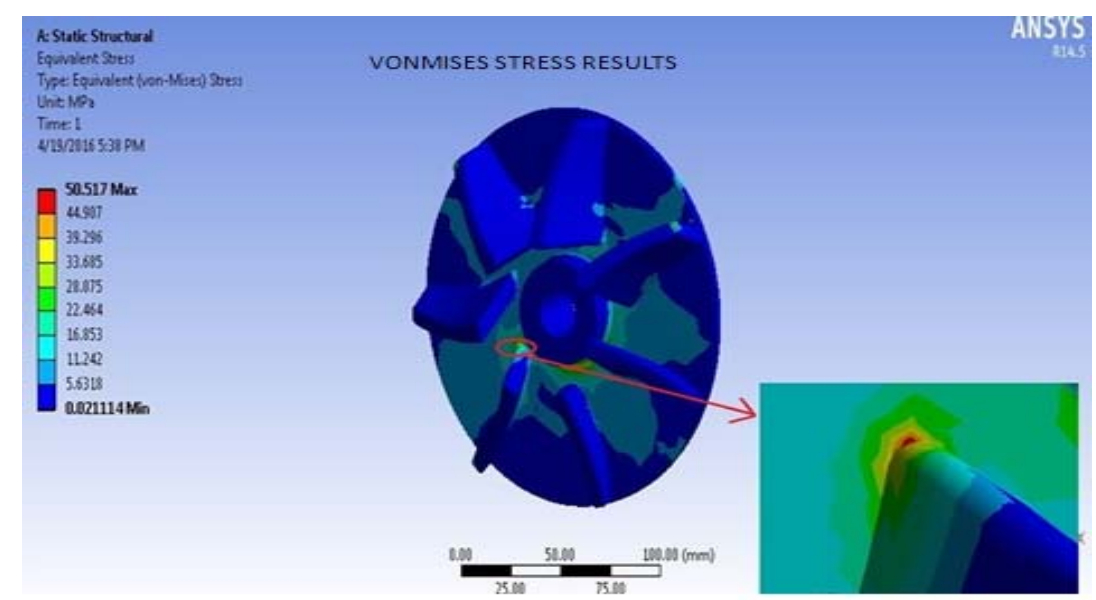

Figure 4: Stress Developed in the Impeller Blade Section

From Standard normal distribution function table, for $\beta_{2}$ value of 2.47 , reliability of the impeller at the blade section $\left(\mathrm{R}_{2}\right)$ is found to be 0.9932 . Total reliability of the impeller is obtained by multiplying $R_{1}$ and $R_{2}$ values. Hence reliability of the impeller is calculated as 0.963 . This reliability value of the impeller calculated using analytical and numerical methods is in agreement with the theoretical as well as empirical values of impeller 
reliability. In general pumping applications such as domestic, agricultural and industrial usages, impeller failure is a rare occurrence. However, the frequency of impeller failure is high in certain applications namely slurry and fertilizer pumping. In this research paper, water is considered as the pumping fluid and hence the impeller reliability is found to be high.

\section{Conclusion}

Criticality of components of the centrifugal pump was calculated in terms of risk priority number which prioritizes the failure mode of components using FMECA. Impeller was identified as the critical component and its reliability was calculated by considering its keyway and blade sections. A mathematical model of the pump was developed to calculate the reliability of keyway section of the impeller by calculating the corrected fatigue strength. Stress value in the blade section was assessed by using finite element analysis. Total reliability of the impeller is calculated by multiplying reliability values of both the sections.

\section{Acknowledgement}

Authors would like to thank the anonymous referees who helped improve the paper.

\section{References}

[1]. Soylemezoglu, A., S. Jagannathan, and C. Saygin. Mahalanobis- Taguchi System as a Multi- Sensor Based Decision Making Prognosis Tool for Centrifugal Pump Failures. IEEE Transactions on Reliability, 2011; 60(4): 864-878.

[2]. H.P. Bloch. Root Cause Analysis of Five Costly Centrifugal Pump Failures. Proceedings of the $7^{\text {th }}$ International Pump Users Symposium, 1990, 15-25.

[3]. Das, G., A.N. Sinha, S.K. Mishra, and D.K. Bhattacharya. Failure Analysis of Counter Shafts of a Centrifugal Pump. Engineering Failure Analysis, 1999; 6: 267-276.

[4]. Espadafor, F.J., J.B. Villanueva, M.T. García, and E.C. Trujillo. Experimental and Dynamic System Simulation and Optimization of a Centrifugal Pump - Coupling Engine System, Part- 1: Failure Identification. Engineering Failure Analysis, 2011; 18: $1-11$.

[5]. Mona Golbabaei Asl, R. Torabi, and S.A. Nourbakhsh. Experimental and FEM Failure Analysis and Optimization of a Centrifugal Pump Volute Casing. Engineering Failure Analysis. 2009; 16: 1996-2003.

[6]. Prakash O., and R.K. Pandey. Failure Analysis of the Impellers of a Feed Pump. Engineering Failure Analysis, 1996; 3(1): 44-52.

[7]. Selvakumar J, and K. Natarajan. Failure Analysis of Centrifugal Pumps Based on Survey. ARPN Journal of Engineering and Technology, 2015; 10(4): 1960-1964.

[8]. Spence. R., and J.A. Teixeira. Investigation into Pressure Pulsations in a Centrifugal Pump Using Numerical Methods Supported by Industrial Tests. Computers and Fluids, 2008; 37: 690-704.

[9]. Zhang Y.M., and Q. Liu. Reliability Based Design of Automobile Components. Proceedings of Mechanical Engineers, 2002; 216(D): 455-470.

[10]. Hussain V.M.S., and V.N.A. Naikan. Reliability Modeling of Rotary Systems Subjected to Imbalance. International Journal of Performability Engineering, 2013; 9(4): 423-432.

J. Selvakumar is working as Assistant Professor in Mechanical Engineering department at S.N.S. College of Technology, Coimbatore, Tamilnadu. He received a Bachelor's 
degree in Mechanical Engineering from Madurai Kamaraj University and Master's degree in Manufacturing Technology from National Institute of Technology, Trichy. He is pursuing research in the area of Reliability improvement of centrifugal pump. His research work is focused on the modification of impeller design and improvement in reliability of centrifugal pump.

K. Natarajan is working as Professor in Mechanical Engineering department at PSG College of Technology, Coimbatore, Tamilnadu. He received a Bachelor's degree in Mechanical Engineering and Master's degree in Engineering design from PSG College of Technology. He holds a Ph.D. in Job-shop scheduling from Bharathiyar University. His academic areas of interest include Design for manufacture and assembly, geometric dimensioning and tolerancing and Job-shop scheduling. 